\title{
Efficacy and safety of concentration-controlled everolimus with reduced-dose cyclosporine in Japanese de novo renal transplant patients: 12-month results
}

Kota Takahashi ${ }^{{ }^{*}}$, Kazuharu Uchida ${ }^{2}$, Norio Yoshimura ${ }^{3}$, Shiro Takahara ${ }^{4}$, Satoshi Teraoka ${ }^{5}$, Rie Teshima ${ }^{6}$, Catherine Cornu-Artis ${ }^{7}$ and Eiji Kobayashi ${ }^{8}$

\begin{abstract}
Background: No study to date has evaluated the efficacy and safety of everolimus with reduced-exposure cyclosporine in Japanese de-novo renal transplant (RTx) patients.

Methods: This 12-month, multicenter, open-label study randomized (1:1) 122 Japanese de-novo RTx patients to either an everolimus regimen ( $1.5 \mathrm{mg} /$ day starting dose (target trough: 3 to $8 \mathrm{ng} / \mathrm{ml})+$ reduced-dose cyclosporine) or a mycophenolate mofetil (MMF) regimen ( $2 \mathrm{~g} /$ day + standard dose cyclosporine). All patients received basiliximab and corticosteroids. Key endpoints at month 12 were composite efficacy failure (treated biopsy-proven acute rejection, graft loss, death, or loss to follow-up) and renal function (estimated glomerular filtration rate; Modification of Diet in Renal Disease-4).

Results: Clear cyclosporine exposure reduction was achieved in the everolimus group throughout the study (52\% reduction at month 12). Month 12 efficacy failure rates showed everolimus $1.5 \mathrm{mg}$ to be non-inferior to MMF (11.5\% vs. 11.5\%). The median estimated glomerular filtration rate at month 12 was $58.00 \mathrm{ml} /$ minute $/ 1.73 \mathrm{~m}^{2}$ in the everolimus group versus $55.25 \mathrm{ml} / \mathrm{minute} / 1.73 \mathrm{~m}^{2}$ in the MMF group $(P=0.063)$. Overall, the incidence of adverse events was comparable between the groups with some differences in line with the known safety profile of the treatments. The everolimus group had a higher incidence of wound healing events and edema, whereas a higher rate of cytomegalovirus infections was reported in the MMF group.

Conclusions: This study confirmed the efficacy of everolimus $1.5 \mathrm{mg} /$ day (target trough: 3 to $8 \mathrm{ng} / \mathrm{ml}$ ) in Japanese RTx patients for preventing acute rejection, while allowing for substantial cyclosporine sparing. Renal function and safety findings were comparable with previous reports from other RTx populations.
\end{abstract}

Trial registration: ClinicalTrials.gov number: NCT00658320

Keywords: Everolimus, Cyclosporine, Renal transplantation, Renal function, Therapeutic drug monitoring

\footnotetext{
* Correspondence: kota@med.niigata-u.ac.jp

'Division of Urology, Department of Regenerative and Transplant Medicine, Graduate School of Medical and Dental Sciences, Niigata University, Niigata 951-8520, Japan

Full list of author information is available at the end of the article
} 


\section{Background}

In Japan, the standard immunosuppressive therapy for renal transplant (RTx) patients comprises a quadruple regimen of basiliximab induction with a calcineurin inhibitor (CNI; cyclosporine A (cyclosporine) or tacrolimus), mycophenolate mofetil (MMF) and corticosteroids [1]. This CNI-based regimen remains the mainstay of immunosuppression following kidney transplantation worldwide [2], but improvements in long-term graft survival are restricted by the chronic nephrotoxicity associated with $\mathrm{CNI}$ therapy $[3,4]$. Intense efforts are being made to develop immunosuppressive strategies that permit early CNI minimization or elimination, potentially leading to a reduction in CNI-related nephrotoxicity and other adverse events (AEs) without compromising acute rejection rates.

Everolimus, a mammalian target of rapamycin (mTOR) inhibitor with potent immunosuppressive and antiproliferative effects [5], has shown good efficacy and tolerability when used in combination with a CNI in de novo kidney transplant recipients [6-14]. However, coadministration of everolimus with standard-exposure CNI therapy adversely affects renal function due to potentiation of CNI-related nephrotoxicity $[7,9,15]$. A number of studies have therefore assessed a variety of everolimus-based, CNI-sparing protocols in order to identify the optimal balance between preventing rejection and preserving graft function [10-14]. Results from large, randomized controlled trials have demonstrated the effectiveness of reduced-exposure cyclosporine with an initial everolimus dose of $1.5 \mathrm{mg}$ /day, subsequently adjusted to target an everolimus trough concentration (C0) of 3 to $8 \mathrm{ng} / \mathrm{ml}[6,12-14]$. The most recent of these trials (A2309) confirmed that this regimen was non-inferior in terms of the primary efficacy endpoint to standardexposure cyclosporine with mycophenolic acid based on a total of 277 patients in each group [14].

These trials, however, were largely conducted in nonAsian patients (87 to $92 \%$ ). Moreover, a high proportion of grafts were from deceased-donor recipients (45 to $100 \%)$, whereas in Japan virtually all solid organ transplants are undertaken with living donors [6,12-14]. A single study has demonstrated that the pharmacokinetics of everolimus are similar in Japanese or non-Japanese volunteers [16], as recommended by the Pharmaceuticals and Medical Devices Agency of Japan [17]. However, clinical trials of a reduced CNI regimen with an everolimus target exposure of 3 to $8 \mathrm{ng} / \mathrm{ml}$ are lacking in Japanese or other Asian populations.

The current randomized, multicenter, 12-month study compared the efficacy and safety of de novo everolimus with reduced-exposure cyclosporine to MMF with standard-dose cyclosporine in Japanese RTx patients.

\section{Methods}

\section{Study design}

This was a 12-month, multicenter, randomized, openlabel study in Japanese adult de novo RTx patients. The study was conducted from February 2008 to August 2010. Following eligibility screening, patients were stratified by donor type (deceased donor or living donor) and randomized (1:1) when the graft function was confirmed just after transplantation into either the everolimus group (everolimus $1.5 \mathrm{mg}$ (targeted C0: 3 to $8 \mathrm{ng} / \mathrm{ml})+$ reduceddose cyclosporine) or the MMF group (MMF $2 \mathrm{~g} /$ day + standard-dose cyclosporine) All patients received basiliximab induction therapy + corticosteroids.

The randomization list was produced by an independent clinical research organization using a validated system that automated the random assignment of treatment arms to randomization numbers.

The independent ethics committee at each center approved this study and written informed consent was obtained from each patient before enrollment. The study was conducted and monitored according to Good Clinical Practice guidelines.

\section{Patients}

Patients aged 18 to 65 years undergoing primary kidney transplantation were eligible. Key exclusion criteria included no evidence of graft function within 24 hours of transplantation, patients of kidneys with a cold ischemia time $>24$ hours; donor age >65 years; patients of multiorgan, ABO-incompatible, positive T-cell cross-match or HLA identical living-related-donor transplants; or most recent anti-HLA class I panel-reactive antibodies $>20 \%$ by complement-dependent cytotoxicity-based assay or $>50 \%$ by flow cytometry or ELISA.

\section{Immunosuppression and other concomitant medications}

The initial dose of the study medication was given within 24 hours (if difficult due to the patient's condition, then within 36 hours) post transplantation. From day 5 onwards, cyclosporine dose adjustments were made based on C0 (determined by local laboratory). Target cyclosporine $\mathrm{C} 0$ concentrations in the everolimus $1.5 \mathrm{mg}$ group started with 100 to $200 \mathrm{ng} / \mathrm{ml}$ and were lowered to 75 to $150 \mathrm{ng} / \mathrm{ml}$ starting at month 2 , then 50 to $100 \mathrm{ng} / \mathrm{ml}$ starting at month 4 , and 25 to $50 \mathrm{ng} / \mathrm{ml}$ from month 6 onwards. In the MMF group, patients started with a cyclosporine C0 target concentration of 200 to $300 \mathrm{ng} / \mathrm{ml}$, which was lowered to 100 to $250 \mathrm{ng} / \mathrm{ml}$ starting at month 2 with this target range to be maintained for the remainder of the study. Everolimus doses were adjusted from day 5 onwards to maintain a $\mathrm{C} 0$ targeted at 3 to $8 \mathrm{ng} / \mathrm{ml}$ (measured by the central laboratory). Therapeutic drug monitoring was mandatory throughout the duration of the study. All patients received basiliximab $(20 \mathrm{mg})$ within 
2 hours prior to transplantation and at day 4, or according to local practice. Corticosteroids were administered according to local practice, at a minimum dose of $5 \mathrm{mg} /$ day for 12 months. Cytomegalovirus (CMV) prophylaxis (including pre-emptive therapy) was mandatory for all cases in which the donor tested positive and the recipient tested negative for CMV. The duration of prophylaxis was not defined in the protocol. All cases other than CMV-positive donors and CMV-negative recipients were treated according to local practice. The drug and dose of the therapy were not defined in the protocol and were according to local practice of the study site. CMV prophylaxis was also recommended following any antibody treatment of acute rejection episodes.

\section{Study endpoints \\ Efficacy}

The primary endpoint was efficacy failure, defined as the composite of treated biopsy-proven acute rejection (BPAR), graft loss, death or loss to follow-up (LTFU) at month 12; LTFU was defined as a patient who did not experience treated BPAR, graft loss or death and whose last day of contact was prior to the month 12 visit. The main secondary endpoint was the composite of graft loss, death or LTFU at month 12 . In all suspected rejection episodes, a graft core biopsy (read by the local and central pathologists according to the updated Banff'97 criteria [18]) was performed within 48 hours. The treated BPAR endpoint was assessed using the central pathologists' reading.

\section{Safety}

The main safety endpoint was renal function at month 12. Renal function was determined by estimated glomerular filtration rate (eGFR) using the Modification of Diet in Renal Disease formula [19]. Other safety assessments included reported AEs and serious AEs as well as clinical laboratory measurements and vital signs.

\section{Statistical analyses}

The primary efficacy analyses were conducted on the intent-to-treat population (all patients randomized). The non-inferiority test was based on confidence intervals (CIs) constructed using the Z-test statistic. One-sided 95\% CIs and two-sided 90\% CIs for the difference in primary efficacy failure rates at 12 months between the everolimus and MMF arms were computed. Everolimus was considered non-inferior to MMF if the upper limit of the $95 \%$ CI was less than 13\%. Kaplan-Meier survival analyses were performed on the rates of composite efficacy failure and its components. For each of the secondary efficacy endpoints, simple event rate estimates (proportion of events) were compared for the everolimus group with the MMF group using Z-statistics based on one-sided $95 \%$ CIs for differences in event rates. The eGFR at 12 months was summarized using descriptive statistics. The Wilcoxon rank-sum test was used to compare the two groups. Except for the renal function analyses, safety analyses were performed on the safety population (patients who received at least one dose of study drug and had a post baseline safety assessment).

\section{Sample size calculation}

The efficacy failure rates at month 12 for the everolimus and MMF groups were assumed to be $19 \%$ and $20 \%$, respectively. Owing to the limited number of RTx patients available, a maximum of 120 patients (60 patients/arm) were expected to be enrolled. A sample size of 60 patients per arm had $61 \%$ power to show everolimus was statistically non-inferior to MMF at one-sided 0.05 levels and non-inferiority margin $13 \%$.

\section{Results}

\section{Patient disposition}

The study population included a total of 122 patients, randomized 1:1 to the everolimus $(n=61)$ and MMF $(n=61)$ groups (intent-to-treat population; safety population). More than $90 \%$ of patients completed the study in both treatment groups and more than $85 \%$ of patients completed the 12-month period on study medication. A total of eight patients discontinued the study at month 12 and all of the study discontinuations were due to withdrawal of consent (Figure 1). Overall, demographic and baseline characteristics were comparable between the groups and are presented in Table 1. The mean age was 42.5 years for the everolimus group and 38.6 years for the MMF group. The majority of patients were male $(75.4 \%$ of everolimus patients and $60.7 \%$ of MMF patients). Donor characteristics were generally similar for both groups. The mean age of donors was 52.3 years for the everolimus group and 55.3 years for the MMF group. Except for one deceased donor each in both the groups, all donors were living and the majority of the donors were living related (59.0\% in the everolimus group and $70.5 \%$ in the MMF group).

\section{Immunosuppressant dose and exposure}

The majority of everolimus patients ( $>85 \%$ from day 7 onwards) were maintained within the targeted everolimus exposure, with the mean everolimus $\mathrm{C} 0$ ranging from 3.4 to $5.5 \mathrm{ng} / \mathrm{ml}$ (Figure 2a). Although a higher proportion of everolimus patients were above the cyclosporine target range versus the MMF group, a clear separation of cyclosporine exposure was achieved between the everolimus group and the MMF group throughout the study period with a $52 \%$ lower mean and median exposure in the everolimus group at month 12 (median: $63.0 \mathrm{ng} / \mathrm{ml}$ and $130.5 \mathrm{ng} / \mathrm{ml}$, respectively) (Figure $2 \mathrm{~b}$ ). The mean MMF doses were decreased up to month 3 


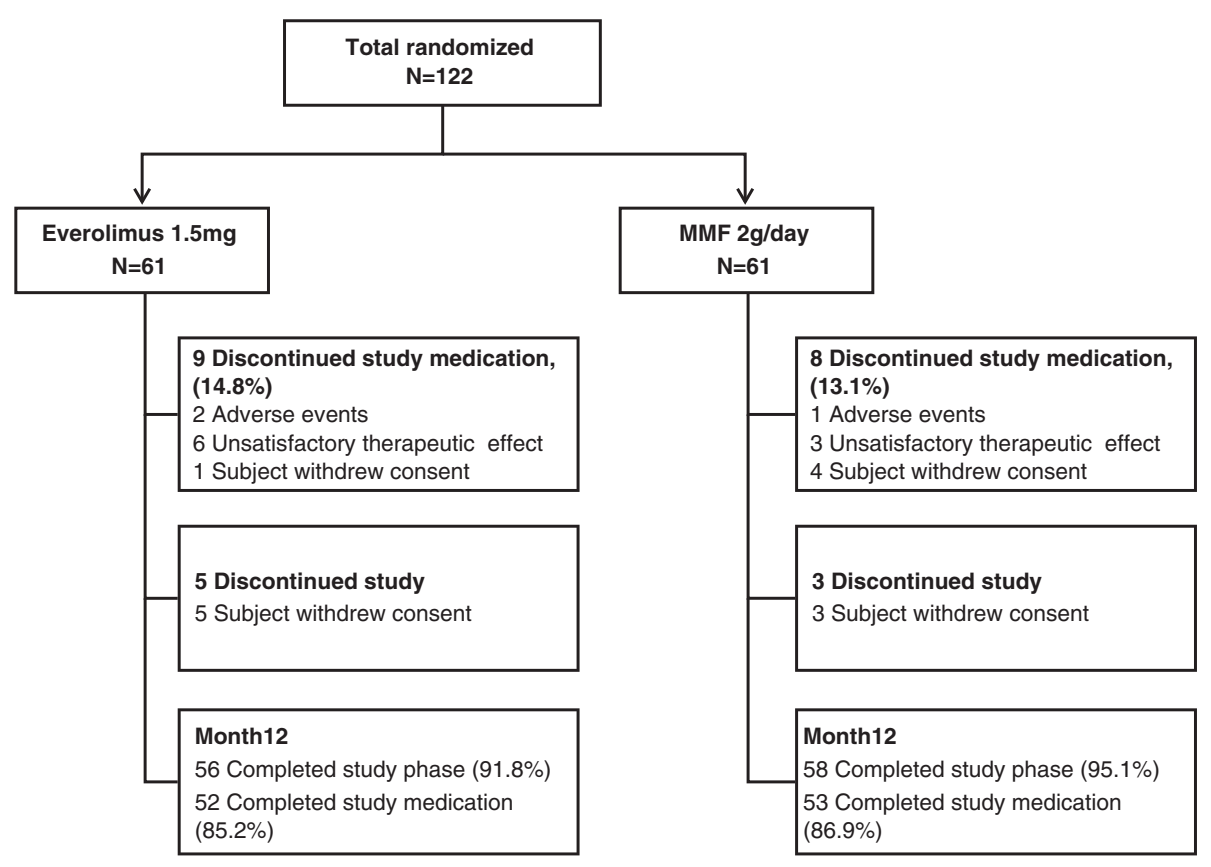

Figure 1 Patient disposition. MMF, mycophenolate mofetil.

due to the adverse events, and subsequently were kept constant throughout the study. The mean \pm standard deviation dose of MMF at month 12 was $1.24 \pm 0.530 \mathrm{~g} /$ day. Mean everolimus and cyclosporine trough levels and average daily doses of everolimus and MMF from day 3 to month 12 are shown in Figure 2a,b and Table 2.

\section{Efficacy}

\section{Primary efficacy endpoint}

Composite efficacy failure event rates at month 12 were identical in both groups (everolimus, 11.5\% and MMF, $11.5 \%$; Table 3). This treatment difference of $0.0 \%$ with the upper limit of the $95 \% \mathrm{CI}$ at $9.5 \%$ was lower than the predefined non-inferiority margin of $13 \%$ confirming noninferiority of the everolimus group to the MMF group. The Kaplan-Meier plot of the proportion of patients free from composite efficacy failure over the 12-month period confirmed similar efficacy for the everolimus and MMF groups (see Additional file 1). There were four patients in the everolimus group and two patients in the MMF group who withdrew informed consent to participate in the study and for whom no further information could be collected. These patients were accounted for as lost to follow-up. There were two patients, one in each group, who developed treated BPAR before discontinuation of the study due to withdrawal of consent, and hence they were not included in the loss to follow-up category.

\section{Secondary efficacy endpoints}

The main secondary efficacy endpoint (combined rate of death, graft loss and LTFU) at month 12 was statistically non-inferior for everolimus (8.2\%) versus MMF (4.9\%). All of the events were due to LTFU with no cases of graft loss or death (Table 3). Treated BPAR (based on central biopsy readings) occurred in three (4.9\%) everolimus patients versus five (8.2\%) MMF patients. The majority of the treated BPARs were of Banff type $1 \mathrm{~A}$ in the everolimus group (Table 3). These results were confirmed based on local biopsy results with treated BPAR occurring in four everolimus patients versus eight MMF patients, with the majority of treated BPARs of type IA or IB.

\section{Safety \\ Renal function}

Median eGFR at month 12 was $58.00 \mathrm{ml} /$ minute $/ 1.73 \mathrm{~m}^{2}$ with everolimus versus $55.25 \mathrm{ml} /$ minute $/ 1.73 \mathrm{~m}^{2}$ with MMF $(P=0.063)$. For both treatment groups, the mean and median eGFR gradually increased at a similar rate during the first month after transplantation. The eGFR levels were higher for the everolimus group through the study but the treatment comparisons did not show any statistically significant differences between the groups at any time point (Table 4; see also Additional file 2). The chronic kidney disease category was used as a guide to evaluate the renal function. The proportion of patients with month 12 eGFR $\geq 60 \mathrm{ml} /$ minute $/ 1.73 \mathrm{~m}^{2}$ was higher with everolimus (46.4\%) compared with MMF 
Table 1 Summary of patient demographics and kidney transplantation background by treatment group (intent-to-treat population)

\begin{tabular}{|c|c|c|}
\hline & Everolimus $1.5 \mathrm{mg}(n=61)$ & MMF $2 \mathrm{~g}(n=61)$ \\
\hline \multicolumn{3}{|l|}{ Recipient characteristics } \\
\hline \multicolumn{3}{|l|}{ Age (years) } \\
\hline Mean \pm standard deviation & $42.5 \pm 14.13$ & $38.6 \pm 11.36$ \\
\hline Median (range) & $42.0(18$ to 65$)$ & 36.0 (20 to 64$)$ \\
\hline \multicolumn{3}{|l|}{ Gender, $n(\%)$} \\
\hline Male & $46(75.4)$ & $37(60.7)$ \\
\hline Female & $15(24.6)$ & $24(39.3)$ \\
\hline \multicolumn{3}{|l|}{ Body mass index $\left(\mathrm{kg} / \mathrm{m}^{2}\right)$} \\
\hline Mean \pm standard deviation & $22.46 \pm 4.03$ & $21.79 \pm 2.78$ \\
\hline Median (range) & 21.97 (15.5 to 37.5$)$ & 21.09 (16.0 to 27.6$)$ \\
\hline \multicolumn{3}{|c|}{ Primary disease leading to transplantation, $n(\%)$} \\
\hline Glomerulonephritis/glomerular disease & $16(26.2)$ & $9(14.8)$ \\
\hline Polycystic disease & $3(4.9)$ & $3(4.9)$ \\
\hline Hypertension/nephrosclerosis & $5(8.2)$ & $2(3.3)$ \\
\hline Diabetes mellitus & $3(4.9)$ & $5(8.2)$ \\
\hline Interstitial nephritis & $2(3.3)$ & $0(0.0)$ \\
\hline Obstructive disorder/reflux & $6(9.8)$ & $3(4.9)$ \\
\hline IgA nephropathy & $11(18.0)$ & $16(26.2)$ \\
\hline Unknown & $8(13.1)$ & $16(26.2)$ \\
\hline Other & $7(11.5)$ & $7(11.5)$ \\
\hline \multicolumn{3}{|l|}{ Current dialysis } \\
\hline None & $12(19.7)$ & $8(13.1)$ \\
\hline Hemodialysis & $42(68.9)$ & $48(78.7)$ \\
\hline Peritoneal dialysis & $7(11.5)$ & $5(8.2)$ \\
\hline \multicolumn{3}{|l|}{ HLA mismatches } \\
\hline 1 & $7(11.5)$ & $2(3.3)$ \\
\hline 2 & $9(14.8)$ & $16(26.2)$ \\
\hline 3 & $25(41.0)$ & $24(39.3)$ \\
\hline$<3$ & $16(26.2)$ & $18(29.5)$ \\
\hline$\geq 3$ & $45(73.8)$ & $43(70.5)$ \\
\hline \multicolumn{3}{|l|}{ Donor characteristics } \\
\hline Mean \pm standard deviation age (years) & $52.3 \pm 8.99$ & $55.2 \pm 8.23$ \\
\hline Deceased heart beating, $n(\%)$ & $1(1.6)$ & $0(0.0)$ \\
\hline Deceased nonheart beating, $n(\%)$ & $0(0.0)$ & $1(1.6)$ \\
\hline Living related, $n$ (\%) & $36(59.0)$ & $43(70.5)$ \\
\hline Living unrelated, $n$ (\%) & $24(39.3)$ & $17(27.9)$ \\
\hline
\end{tabular}

$H L A$, human leukocyte antigen; $\lg A$, immunoglobulin $\mathrm{A} ; M M F$, mycophenolate mofetil.

(32.8\%), but it was not statistically significant $(P=0.152)$ (Table 4).

\section{Adverse events and laboratory parameters}

The overall incidence of AEs was comparable between the treatment groups (Table 5). The proportion of patients reporting any serious AEs was approximately
$10 \%$ higher for the MMF group (54.1\%) versus the everolimus group (44.3\%) (risk ratio $(\mathrm{RR})=0.82(95 \%$ $\mathrm{CI}=0.568,1.178)$ ). A higher proportion of the MMF patients $(26.2 \%)$ versus the everolimus (19.7\%) patients $(\mathrm{RR}=0.75(95 \% \mathrm{CI}=0.388,1.450))$ experienced serious infections, particularly serious CMV infections $(18.0 \%$ vs. $1.6 \%$, respectively, $\mathrm{RR}=0.09(0.012,0.683))$, gastroenteritis 

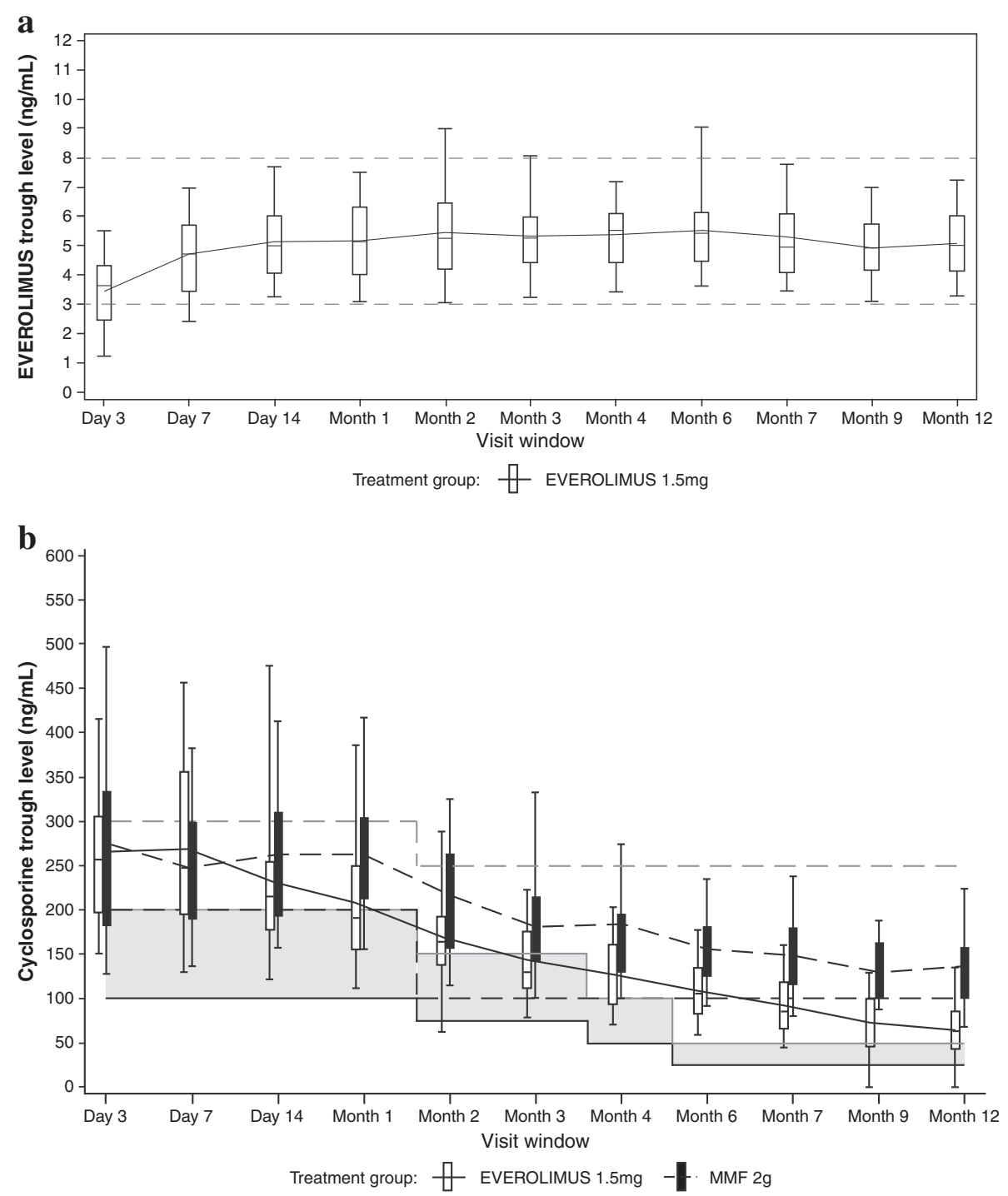

Figure 2 Mean everolimus and cyclosporine trough levels over time. (a) Mean everolimus trough levels over time for the everolimus $1.5 \mathrm{mg}$ group (safety population). At each visit the mean is shown and these are joined with horizontal lines. Whiskers are the 5th and 95 th percentiles. Target levels are displayed. (b) Mean cyclosporine trough levels for all treatment groups over time (safety population). At each visit the mean is shown and these are joined with horizontal lines. Whiskers are the 5th and 95th percentiles. The target ranges are also displayed with solid lines (lower limit) and broken lines (upper limit) for comparison with the values seen. MMF, mycophenolate mofetil.

(6.6\% vs. $3.3 \%$, respectively), and herpes zoster infections (3.3\% vs. $0 \%$, respectively).

The most common AEs were nasopharyngitis, hyperlipidemia, constipation, acne and hypertension, and the majority of AEs (>85\% in either group) were mild or moderate in severity. AEs/infections leading to discontinuation of the study drug occurred in $4.9 \%$ of the patients in the everolimus group (pyrexia, diffuse large B-cell lymphoma and membranous glomerulonephritis) versus $1.6 \%$ in the MMF group (electrolyte imbalance and hirsutism) (Table 5). A higher proportion of the MMF patients (85.2\%) versus the everolimus patients (24.6\%) had AEs requiring study drug dose adjustment/interruption
(Table 5). This was mostly due to infections $(52.5 \%$ in MMF group vs. $13.1 \%$ in everolimus group). The incidence of any infection was higher with MMF (93.4\%) versus everolimus (82.0\%). Viral infections were more frequent in the MMF group (80.3\%) compared with the everolimus group $(27.9 \%)(\mathrm{RR}=0.35$ (95\% $\mathrm{CI}=0.227,0.529))$, predominantly due to the higher rate of CMV (68.9\% vs. $14.8 \%$ ) (see Additional file 3). Only one patient in the everolimus group (CMV-positive donor/CMV-negative recipient) and six patients in the MMF group (three CMV-positive donor/CMV-negative recipient and three CMV-positive donor/CMV-positive recipient) received CMV prophylaxis (see Additional file 4). 
Table 2 Average daily doses of everolimus ( $\mathrm{mg} /$ day) and mycophenolate mofetil (g/day) by visit window (safety population)

\begin{tabular}{lllll}
\hline & \multicolumn{2}{l}{ Everolimus $\mathbf{1 . 5} \mathbf{~ m g}(\boldsymbol{n}=\mathbf{6 1})$} & \multicolumn{2}{l}{ MMF $(\boldsymbol{n}=\mathbf{6 1})$} \\
\hline Visit window & $\boldsymbol{n}$ & Mean $\mathbf{\text { SD }}$ & $\boldsymbol{n}$ & Mean $\mathbf{\text { SD }}$ \\
Day 3 & 61 & $1.49(0.0 .048)$ & 61 & $1.95(0.194)$ \\
Day 7 & 60 & $1.70(0.447)$ & 61 & $1.88(0.297)$ \\
Month 1 & 57 & $1.72(0.539)$ & 60 & $1.70(0.475)$ \\
Month 3 & 55 & $1.70(0.628)$ & 58 & $1.33(0.606)$ \\
Month 4 & 55 & $1.68(0.611)$ & 56 & $1.22(0.595)$ \\
Month 6 & 55 & $1.65(0.602)$ & 55 & $1.28(0.583)$ \\
Month 7 & 55 & $1.61(0.610)$ & 54 & $1.28(0.570)$ \\
Month 9 & 54 & $1.68(0.656)$ & 54 & $1.25(0.530)$ \\
Month 12 & 53 & $1.68(0.705)$ & 53 & $1.24(0.530)$ \\
\hline
\end{tabular}

$M M F$, mycophenolate mofetil; $S D$, standard deviation.

The incidence of toxic nephropathy reported as cyclosporine nephrotoxicity was numerically higher in the everolimus group (21.3\%) than in the MMF group (9.8\%) $(\mathrm{RR}=2.17(95 \% \mathrm{CI}=0.881,5.329))$ (Table 5). Malignancies were reported for two (3.3\%) everolimus patients (one patient with thyroid cancer and one patient with B-cell lymphoma), whereas no malignancies were reported in MMF patients. Wound healing events were reported for 24 (39.3\%) everolimus patients and seven (11.5\%) MMF patients $(\mathrm{RR}=3.43(95 \% \mathrm{CI}=1.598,7.357))$. Wound events were reported as serious AEs in three (4.9\%) everolimus patients and one (1.6\%) MMF patient. Most of the wound healing events reported were mild $(4.9 \%$ and $1.6 \%$ ) to moderate (34.4\% and $8.2 \%$ ), with $0 \%$ and $1.6 \%$ of events classified as severe in the everolimus and the MMF groups, respectively. The most common wound healing $\mathrm{AE}$ was lymphocele, which was reported for seven (11.5\%) everolimus patients and two (3.3\%) MMF patients. Impaired healing was reported as an $\mathrm{AE}$ for six (9.8\%) everolimus patients and one (1.6\%) MMF patient. Edema occurred in 20 (32.8\%) everolimus and eight MMF patients $(13.8 \%)(\mathrm{RR}=2.50(95 \% \mathrm{CI}=1.194,5.235))$. Proteinuria was reported as an AE in eight (13.1\%) everolimus patients and five (8.2\%) MMF patients $(\mathrm{RR}=1.60(95 \% \mathrm{CI}=0.555,4.616))($ Table 5$)$. The urinary protein:creatinine ratio in the everolimus group was slightly higher than in the MMF group throughout the study (median at month 12 was $135.0 \mathrm{mg} / \mathrm{g}$ and $65.0 \mathrm{mg} / \mathrm{g}$, respectively). AEs generally associated with cyclosporine were more frequently reported in the MMF group versus the everolimus group (Table 5).

The mean and median systolic blood pressure and diastolic blood pressure decreased from baseline for both treatment groups (Table 6). Low neutrophil counts $\left(\leq 1,000 / \mathrm{mm}^{3}\right)$ were observed for two $(3.3 \%)$ MMF patients. Hyperlipidemia was reported in 28 (45.9\%) everolimus patients and 19 (31.1\%) MMF patients, and hypercholesterolemia was reported for seven (11.5\%) everolimus patients and six (9.8\%) MMF patients. High triglyceride levels $(\geq 750 \mathrm{mg} / \mathrm{dl})$ were reported for one (1.6\%) everolimus patient and high total cholesterol levels $(>350 \mathrm{mg} / \mathrm{dl})$ for two $(3.3 \%)$

Table 3 Summary of efficacy parameters by treatment (intent-to-treat population)

\begin{tabular}{|c|c|c|c|}
\hline & $\begin{array}{l}\text { Everolimus } 1.5 \mathrm{mg} \\
(n=61)\end{array}$ & $\begin{array}{l}\text { MMF } 2 \mathrm{~g} \\
(n=61)\end{array}$ & Comparison of everolimus vs. MMF \\
\hline \multicolumn{4}{|l|}{ Efficacy endpoints } \\
\hline Primary composite endpoint (at 12 months) ${ }^{a}$ & $7(11.5)$ & $7(11.5)$ & Difference in rates $0.0 \%(9.5 \%),(-9.49,9.49) P=0.012^{d}$ \\
\hline Treated BPAR & $3(4.9)$ & $5(8.2)$ & \\
\hline Graft loss & 0 & 0 & \\
\hline Death & 0 & 0 & \\
\hline Loss to follow-up ${ }^{b}$ & $4(6.6)$ & $2(3.3)$ & \\
\hline \multicolumn{4}{|l|}{ Secondary efficacy endpoints } \\
\hline \multicolumn{4}{|l|}{ Patients with treated BPAR by Banff grade } \\
\hline IA & $2(3.3)$ & $2(3.3)$ & \\
\hline $\mathrm{IB}$ & 0 & $1(1.6)$ & \\
\hline$\| A$ & $1(1.6)$ & $2(3.3)$ & \\
\hline Graft loss or death (month 12) & 0 & 0 & \\
\hline Graft loss, death or loss to follow-up ${ }^{c}$ (month 12) & $5(8.2)$ & $3(4.9)$ & $3.3 \%(10.6 \%), P=0.015^{d}$ \\
\hline
\end{tabular}

Data presented as $n(\%) .{ }^{a}$ Composite of treated BPAR, graft loss, death, or loss to follow-up. For the individual components of the composite endpoint, patients are counted for the first event to occur. ${ }^{\mathrm{b}} \mathrm{A}$ loss to follow-up in the primary endpoint is a patient who did not experience treated BPAR, graft loss, or death and

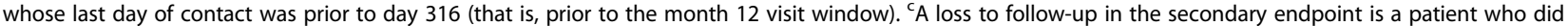
not experience graft loss or death and whose last day of contact was prior to day 316 (that is, prior to the month 12 visit window). Note that for patients meeting the composite efficacy endpoint, patients are recorded by the individual. ${ }^{\mathrm{d}}$ Z-test for everolimus - MMF $\geq 0.13$ (non-inferiority test, $P$ value for non-inferiority test is for a one-sided test and should be compared with the 0.05 significance level. BPAR, biopsy-proven acute rejection; MMF, mycophenolate mofetil. 
Table 4 Renal function over 12 months (intent-to-treat population)

\begin{tabular}{|c|c|c|c|c|c|c|c|}
\hline \multirow{2}{*}{$\begin{array}{l}\text { Visit } \\
\text { window }\end{array}$} & \multicolumn{3}{|c|}{ Everolimus $1.5 \mathrm{mg}(n=61)$} & \multirow[b]{2}{*}{$P$ value ${ }^{a}$ vs. MMF } & \multicolumn{3}{|c|}{ MMF 2 g $(n=61)$} \\
\hline & $n$ & Mean (SD) & Median (range) & & $n$ & Mean (SD) & Median (range) \\
\hline \multicolumn{8}{|c|}{ eGFR (MDRD) (ml/minute $/ 1.73 \mathrm{~m}^{2}$ ) } \\
\hline Baseline & 61 & $12.17(6.23)$ & $10.70(4.7$ to 41.1$)$ & 0.420 & 61 & $14.00(8.37)$ & $11.00(2.7$ to 41.1$)$ \\
\hline Month 1 & 56 & $63.10(25.441)$ & 58.40 (18.5 to 123.3$)$ & 0.685 & 60 & $60.53(19.339)$ & 57.25 (23.5 to 14.7$)$ \\
\hline \multirow[t]{2}{*}{ Month 12} & 56 & 62.09 (18.993) & 58.00 (17.8 to 123.3$)$ & 0.063 & 58 & $56.34(15.227)$ & 55.25 (26.1 to 111.8$)$ \\
\hline & $<30$ & $\geq 30$ to $<60$ & $\geq 60$ & $P$ value vs. MMF & $<30$ & $\geq 30$ to $<60$ & $\geq 60$ \\
\hline \multicolumn{8}{|c|}{ Incidence rates of patients within renal function (eGFR MDRD) categories ( $n /$ month, \%) } \\
\hline Month 1 & $5 / 56(8.9)$ & $26 / 56(46.4)$ & 25/56 (44.6) & 0.541 & $1 / 60(1.7)$ & $31 / 60(51.7)$ & $28 / 60(46.7)$ \\
\hline Month 12 & $1 / 56(1.8)$ & 29/56 (51.8) & $26 / 56(46.4)$ & 0.152 & $1 / 58(1.7)$ & $38 / 58(65.5)$ & 19/58 (32.8) \\
\hline
\end{tabular}

${ }^{a}$ Wilcoxon rank-sum test comparing everolimus and MMF values. eGFR, estimated glomerular filtration rate; MDRD, Modification of Diet in Renal Disease; MMF, mycophenolate mofetil; SD, standard deviation.

everolimus patients and one (1.6\%) MMF patient (Table 6).

\section{Discussion}

Results of this randomized study in Japanese de novo kidney transplant patients indicate that everolimus with reduced-exposure cyclosporine provides similar efficacy, renal function and safety to MMF with standardexposure cyclosporine over the first 12 months post transplant. These outcomes were achieved with $\sim 52 \%$ lower cyclosporine A trough concentration in the everolimus treatment group versus the standard therapy arm. The findings from this trial are comparable with those reported in a large, predominantly Caucasian population in the recent A2309 study [12].

There were no graft losses or deaths in either treatment group, and rates of treated BPAR at 12 months were notably low in both treatment arms (everolimus $\sim 5 \%$, MMF 8\%). The low incidence of rejection partly reflects the almost universal use of living donors in our cohort, but slightly higher cyclosporine exposure than in the recent A2309 study [12] may also have contributed. This was balanced by a somewhat lower mean everolimus trough concentration in the current trial. Recipient demographics were broadly similar in the two studies, although donor age was slightly older in the current trial.

The key renal endpoint, eGFR (Modification of Diet in Renal Disease) at month 12, did not differ significantly between the two treatment groups $(P=0.063)$ but was numerically higher in the everolimus cohort throughout the trial. As might be expected in our living-donor population, the mean eGFR was slightly higher than in the larger A2309 study, but the pattern of difference between treatment groups was comparable. The A2309 trial also showed the mean eGFR to be numerically higher in the everolimus-treated patients at all time points, but in that larger study population the betweengroup difference became significant at months 1, 6, 7 and 9. In both trials, the proportion of patients with
CKD stage $\geq 4$ (that is, eGFR $\geq 60 \mathrm{ml} /$ minute $/ 1.73 \mathrm{~m}^{2}$ ) at month 12 was higher in the everolimus group versus the mycophenolic acid cohort, an encouraging finding since renal function at 12 months post RTx is recognized as predictive of long-term renal function [20]. No everolimus-treated patient was reported to have severe proteinuria in our population. The incidence of toxic nephropathy was higher with everolimus versus MMF, a difference that arose during the first 14 days after transplantation. In that 2-week period, mean cyclosporine trough levels in the everolimus group were no different from those in the MMF group. Since everolimus is known to potentiate cyclosporine-related nephrotoxicity when cyclosporine exposure is high $[7,9,15]$, the acute nephrotoxicity that was observed may probably have been largely caused by high cyclosporine exposure. Previously it has been reported that CNI-associated acute nephrotoxicity early after transplant can be resolved with dose reduction or interruption [21,22]. In this study with subsequent reductions in cyclosporine exposure, the eGFR for the everolimus group was higher than for the MMF group at month 12 post transplantation, and no difference in the rate of chronic nephrotoxicity was reported between the two groups, highlighting the importance of prompt and adequate CNI reduction in the presence of everolimus.

The overall safety profile of everolimus was similar to that seen in previous studies and no AEs were identified that appeared to be specific to Japanese patients. Hyperlipidemia, insomnia, increased alkaline phosphatase, increased luteinizing hormone and follicle stimulating hormone, wound healing events and edema were more frequent with everolimus, while the incidences of CMV infection, nasopharyngitis, constipation and acne were all higher with MMF. The incidence of serious AEs was approximately $10 \%$ lower with everolimus compared with MMF, with a notably lower rate of CMV reported as serious infections among everolimus-treated patients (1.6\% vs. $18.0 \%$ of MMF-treated patients). A reduced 
Table 5 Summary of adverse events over 12 months of treatment (safety population)

\begin{tabular}{|c|c|c|c|}
\hline & Everolimus $1.5 \mathrm{mg}(n=61)$ & MMF $2 \mathrm{~g}(n=61)$ & Risk ratio $(95 \% \mathrm{Cl})$ \\
\hline Any adverse event & $61(100)$ & $61(100)$ & - \\
\hline Serious adverse events & $27(44.3)$ & $33(54.1)$ & $0.82(0.568,1.178)$ \\
\hline Severe adverse events & $7(11.5)$ & $8(13.1)$ & $0.88(0.338,2.263)$ \\
\hline Adverse events leading to study drug discontinuation ${ }^{a}$ & $3(4.9 \%)$ & $1(1.6 \%)$ & $3.00(0.321,28.044)$ \\
\hline Adverse events leading to study drug dose adjustment/interruption & $15(24.6)$ & $52(85.2)$ & $0.29(0.184,0.453)$ \\
\hline \multicolumn{4}{|c|}{ Most frequently reported adverse events and infections ( $\geq 20 \%$ of patients in any treatment group) ${ }^{b}$} \\
\hline Hyperlipidemia & $28(45.9)$ & $19(31.1)$ & $1.47(0.928,2.339)$ \\
\hline Nasopharyngitis & $21(34.4)$ & $26(42.6)$ & $0.81(0.514,1.270)$ \\
\hline Constipation & $19(31.1)$ & $27(44.3)$ & $0.70(0.441,1.123)$ \\
\hline Hypertension & $19(31.1)$ & $18(29.5)$ & $1.06(0.616,1.808)$ \\
\hline Insomnia & $17(27.9)$ & $9(14.8)$ & $1.89(0.914,3.903)$ \\
\hline Acne & $15(24.6)$ & $22(36.1)$ & $0.68(0.393,1.184)$ \\
\hline Headache & $13(21.3)$ & $9(14.8)$ & $1.44(0.667,3.127)$ \\
\hline Toxic nephropathy & $13(21.3)$ & $6(9.8)$ & $2.17(0.881,5.329)$ \\
\hline Blood alkaline phosphatase increased & $13(21.3)$ & $7(11.5)$ & $1.86(0.796,4.334)$ \\
\hline Pyrexia & $13(21.3)$ & $12(19.7)$ & $1.08(0.538,2.181)$ \\
\hline Iron deficiency anemia & $12(19.7)$ & $13(21.3)$ & $0.92(0.458,1.858)$ \\
\hline Diarrhea & $11(18.0)$ & $15(24.6)$ & $0.73(0.367,1.466)$ \\
\hline Increased blood creatinine & $11(18.0)$ & $14(23.0)$ & $0.79(0.388,1.591)$ \\
\hline Hyperuricemia & $7(11.5)$ & $13(21.3)$ & $0.54(0.231,1.257)$ \\
\hline Cytomegalovirus test positive & $4(6.6)$ & $19(31.1)$ & $0.21(0.076,0.583)$ \\
\hline Cytomegalovirus infection & $3(4.9)$ & $21(34.4)$ & $0.14(0.045,0.454)$ \\
\hline \multicolumn{4}{|l|}{ Other adverse events of interest } \\
\hline \multicolumn{4}{|l|}{ Cyclosporine-associated adverse events } \\
\hline Gingival hypertrophy & $0(0.0)$ & $2(3.3 \%)$ & - \\
\hline Gingival injury & $0(0.0)$ & $1(1.6 \%)$ & - \\
\hline Gingivitis & $0(0.0)$ & $1(1.6 \%)$ & - \\
\hline Tremor & $4(6.6 \%)$ & $1(1.6 \%)$ & $4.00(0.460,34.767)$ \\
\hline Hirsutism & $1(1.6 \%)$ & $4(6.6 \%)$ & $0.25(0.029,2.173)$ \\
\hline Hypertrichosis & $2(3.3 \%)$ & $3(4.9 \%)$ & $0.67(0.115,3.850)$ \\
\hline \multicolumn{4}{|l|}{ Everolimus-associated adverse events } \\
\hline Wound-healing event ${ }^{c}$ & $24(39.3)$ & $7(11.5)$ & $3.43(1.598,7.357)$ \\
\hline New-onset diabetes ${ }^{c}$ & $7(11.5)$ & $3(4.9)$ & $2.33(0.633,8.606)$ \\
\hline Edema events $^{c}$ & $20(32.8)$ & $8(13.1)$ & $2.50(1.194,5.235)$ \\
\hline Stomatitis events ${ }^{c}$ & $14(23.0)$ & $10(16.4)$ & $1.40(0.675,2.904)$ \\
\hline Blood luteinizing hormone increased & $9(14.8)$ & $0(0.0)$ & - \\
\hline Blood follicle stimulating hormone increased & $8(13.1)$ & $1(1.6)$ & $8.00(1.032,62.040)$ \\
\hline Proteinuria & $8(13.1)$ & $5(8.2)$ & $1.60(0.555,4.616)$ \\
\hline \multicolumn{4}{|l|}{ Investigator-reported severity } \\
\hline Mild & $6(9.8)$ & $3(4.9)$ & $2.00(0.524,7.636)$ \\
\hline Moderate & $2(3.3)$ & $1(1.6)$ & $2.00(0.186,21.482)$ \\
\hline Severe & $0(0.0)$ & $1(1.6)$ & - \\
\hline
\end{tabular}

Data are presented as $n$ (\%). ${ }^{\mathrm{a}}$ For patients with adverse events leading to discontinuation of study medication (recorded on the AE/Infection CRF page), the primary discontinuation reason (recorded on the End of Treatment CRF page) is not necessarily 'AE(s)'; rather, it may be 'abnormal laboratory result(s)' or 'unsatisfactory therapeutic effect'. ' By preferred term. 'Events were identified from a predefined list of adverse event preferred terms. MMF, mycophenolate mofetil. 
Table 6 Vital signs, hematological and biochemical abnormalities over 12 months of treatment (safety population)

\begin{tabular}{|c|c|c|}
\hline & $\begin{array}{c}\text { Everolimus } 1.5 \\
\mathrm{mg}(n=61)\end{array}$ & $\begin{array}{l}\text { MMF } 2 \mathrm{~g} \\
(n=61)\end{array}$ \\
\hline \multicolumn{3}{|l|}{$\mathrm{SBP}(\mathrm{mmHg})$} \\
\hline$\leq 90 \mathrm{mmHg}$ or $<75 \mathrm{mmHg}^{\mathrm{a}}$ & $1(1.6)$ & $0(0.0)$ \\
\hline$\geq 180 \mathrm{mmHg}$ or $>200 \mathrm{mmHg}^{\mathrm{b}}$ & $9(14.8)$ & $6(9.8)$ \\
\hline \multicolumn{3}{|l|}{$\mathrm{DBP}(\mathrm{mmHg})$} \\
\hline$\leq 50 \mathrm{mmHg}$ or $<40 \mathrm{mmHg}$ & $4(6.6)$ & $0(0.0)$ \\
\hline$\geq 105 \mathrm{mmHg}$ or $>115 \mathrm{mmHg}$ & $14(23.0)$ & $16(26.2)$ \\
\hline \multicolumn{3}{|l|}{ Hematology } \\
\hline Platelets, low: $<50 \mathrm{k} / \mathrm{mm}^{3}$ & $0(0.0)$ & $1(1.6)$ \\
\hline Eosinophils, high: $\geq 12 \%$ & $1(1.6)$ & $1(1.6)$ \\
\hline Hemoglobin, low: $<7 \mathrm{~g} / \mathrm{dl}$ & $5(8.2)$ & $5(8.2)$ \\
\hline Lymphocytes, low: $\leq 1,000 / \mathrm{mm}^{3}$ & $48(78.7)$ & $56(91.8)$ \\
\hline \multicolumn{3}{|l|}{ Leukocytes } \\
\hline Low: $\leq 2.0 \mathrm{k} / \mathrm{mm}^{3}$ & $0(0.0)$ & $1 / 61(1.6)$ \\
\hline High: $\geq 16 \mathrm{k} / \mathrm{mm}^{3}$ & $32(52.5)$ & $20(32.8)$ \\
\hline Neutrophils, low: $\leq 1,000 / \mathrm{mm}^{3}$ & $0(0.0)$ & $2(3.3)$ \\
\hline \multicolumn{3}{|l|}{ Lipids } \\
\hline Total cholesterol, high: $\geq 350 \mathrm{mg} / \mathrm{dl}$ & $2(3.3)$ & $1(1.6)$ \\
\hline Triglycerides, high: $\geq 750 \mathrm{mg} / \mathrm{dl}$ & $1(1.6)$ & $0(0.0)$ \\
\hline \multicolumn{3}{|l|}{ Cholesterol (total)/HDL ratio } \\
\hline High: $\geq 5$ and $\leq 7$ & $24(39.3)$ & $17(27.9)$ \\
\hline Very high: $>7$ & $5(8.2)$ & $3(4.9)$ \\
\hline Lipid modifying agents & $42(68.9)$ & $24(39.3)$ \\
\hline $\begin{array}{l}\text { Number of patients with normalized } \\
\text { cholesterol values after statin treatment } \\
\text { (n/month) }\end{array}$ & 16/18 (88.9) & $6 / 7(85.7)$ \\
\hline $\begin{array}{l}\text { Number of patients with normalized } \\
\text { triglyceride values after statin treatment }\end{array}$ & $9 / 12(75)$ & $3 / 4(75)$ \\
\hline
\end{tabular}

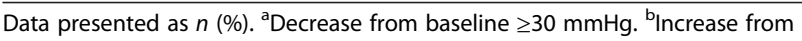
baseline $\geq 30 \mathrm{mmHg}$. $D B P$, diastolic blood pressure; $H D L$, high-density lipoprotein; $S B P$, systolic blood pressure.

incidence of CMV infection with everolimus compared with mycophenolic acid has been reported previously in kidney transplantation [12,15], although the betweengroup difference in CMV infection in the present study was greater than in previous trials. This may have resulted from more frequent CMV testing at Japanese centers than is standard elsewhere. Reports in preclinical studies state that mTOR inhibition may promote differentiation of antiviral memory CD8 T cells [23,24], upregulate proinflammatory cytokines, downregulate anti-inflammatory cytokines, and boost major histocompatibility complex antigen presentation [25] effects that would be expected to contribute to reduced viral infection.

As a consequence of the low number of kidney transplants performed each year in Japan, the study size was small, with relatively low statistical power. However, the findings were remarkably similar to those observed in the large A2309 study, which used a similar design. As in A2309, the patients in this study were selected to be of relatively low immunological risk, and in addition were almost exclusively recipients of a living-donor graft. The results may therefore not be generalizable to a wider population. The core study was 12 months in duration, which may not have been adequate to fully examine the effect of an everolimus-based regimen on renal function. An extension phase will provide data to 24 months. One should also note that although an openlabel design was mandatory because of the need to adjust drug doses based on trough concentrations in each patient, this does introduce the risk of reporting bias, particularly for AEs.

In conclusion, as compared with other countries, currently there are limited immunosuppressant options available for RTx patients in Japan. This study in de novo Japanese RTx patients demonstrated that everolimus (targeting a $\mathrm{C} 0$ of 3 to $8 \mathrm{ng} / \mathrm{ml}$ ) with minimized cyclosporine exposure was non-inferior to MMF with standardexposure cyclosporine in preventing efficacy failure to 12 months post transplant. Renal function did not differ significantly between the two groups, but was numerically higher in the everolimus cohort throughout the study. No safety concerns specific to Japanese patients were observed. While relatively small, this trial benefits from a multicenter, randomized design and is the first to validate the results of the large A2309 study in a Japanese population. The findings indicate that cyclosporine minimization facilitated by everolimus is a viable immunosuppressive regimen for Japanese recipients of a kidney transplant and may also contribute to the long-term maintenance of good graft function and patient survival.

\section{Additional files}

Additional file 1: Figure showing a Kaplan-Meier plot for the proportion of patients free from composite efficacy failure to cutoff date (intent-to-treat population - 12-month analysis).

Additional file 2: Figure showing the eGFR (Modification of Diet in Renal Disease (MDRD)) over time by treatment group (intent-totreat population). At each visit box-plots are displayed, with the means joined by a horizontal line. The whiskers are shown at the 10th and 90th percentiles. EMV, everolimus.

Additional file 3: Table presenting a summary of infections over 12 months of treatment (safety population).

Additional file 4: Table presenting incidence rates of patients with CMV infections by donor/recipient CMV status at baseline and CMV prophylaxis (safety population).

\section{Abbreviations}

AE: adverse event; BPAR: biopsy-proven acute rejection; C0: trough concentration; Cl: confidence interval; CMV: cytomegalovirus; CNI: calcineurin inhibitors; ELISA: enzyme-linked immunosorbent assay; eGFR: estimated glomerular filtration rate; LTFU: Ioss to follow-up; MMF: mycophenolate 
mofetil; mTOR: mammalian target of rapamycin; RR: risk ratio; RTx: renal transplant

\section{Competing interests}

KT has links with the Novartis Speakers Bureau, and is an advisor. KU has links with Novartis Speakers Bureau. NY has links with Novartis Speakers Bureau. STa has links with Novartis Speakers Bureau. STe has links with Novartis Speakers Bureau. RT is a Novartis employee. CC-A is a Novartis employee. EK has links with Novartis Speakers Bureau for grant/research support and as an advisor, and a special advisor for Otsuka Pharmaceutical Factory Inc. (Naruto, Japan) from 2009.

\section{Authors' contributions}

KT, KU, STa, NY, STe, and EK participated in the research design and performance of the research. RT and CC-A performed the data analysis. All authors read and approved the final manuscript.

\section{Acknowledgements}

This study was supported by Novartis Pharma K.K. Japan. The authors thank Heike Schwende, PhD, Novartis Pharma AG Switzerland, for organizing the development of the manuscript. They also thank Swati Machwe, PhD, and Raghuraj Puthige, PhD, Novartis Healthcare Pvt. Ltd India for editorial assistance.

Study sites and principal investigators: Kota Takahash (Niigata University Medical and Dental Hospital), Noritoshi Amada (Sendai Shakaihoken Hospital), Takashi Yagisawa (Jichi Medical University Hospital), Kenji Yuzawa (National Hospital Organization Mito Medical Center), Takashi Kenmochi (National Hospital Organization Chiba-East Hospital), Satoshi Teraoka (Tokyo Women's Medical University Hospital), Shohei Fuchinoue (Tokyo Women's Medical University Hospital), Kazunari Tanabe (Tokyo Women's Medical University Hospital), Atsushi Aikawa (Toho University Omori Medical Center), Ken Nakagawa (Keio University Hospital), Kazunari Yoshida (Kitasato University Hospital), Kazuharu Uchida (Nagoya Daini Red Cross Hospital), Tsuneo Kinukawa (Shakai Hoken Chukyo Hospital), Kiyotaka Hoshinaga (Fujita Health University Hospital), Shinichi Ito (Gifu University Hospital), Norio Yoshimura (University Hospital, Kyoto Prefectural University of Medicine), Shiro Takahara (Osaka University Hospital), Tatsuya Nakatani (Osaka City University Hospital), Masato Fujisawa (Kobe University Hospital), Shinichirou Tanaka (National Hospital Organization Okayama Medical Center), Hidehisa Kitada (Kyushu University Hospital), and Shigeru Satoh (Akita University Hospital).

Central biopsy committee members: Kunio Morozumi (Nagoya Daini Red Cross Hospital), Yutaka Yamaguchi (Yamaguchi Pathology Laboratory), Michio Nagata (University of Tsukuba), and Asami Takeda (Nagoya Daini Red Cross Hospital).

Medical advisor: Eiji Kobayashi (Jichi Medical University).

\section{Author details}

${ }^{1}$ Division of Urology, Department of Regenerative and Transplant Medicine, Graduate School of Medical and Dental Sciences, Niigata University, Niigata 951-8520, Japan. ²Department of Organ Transplant Surgery, Aichi Medical University, Aichi 480-1195, Japan. ${ }^{3}$ Transplantation and Regenerative Surgery, Graduate School of Medical Science, Kyoto Prefectural University of Medicine, Kyoto 602-8566, Japan. ${ }^{4}$ Department of Advanced Technology for Transplantation, Osaka University Graduate School of Medicine, Osaka 565-0871, Japan. ${ }^{5}$ Department of Transplant Surgery, International University of Health and Welfare Atami Hospital, Shizuoka 413-0012, Japan. ${ }^{6}$ Novartis Pharma K.K, Tokyo 106-8618, Japan. ${ }^{7}$ Novartis Pharma AG, Basel CH-4002, Switzerland. ${ }^{8}$ Division of Development of Advanced Treatment, Center for Development of Advanced Medical Technology, Jichi Medical University, Tochigi 329-0498, Japan.

Received: 13 March 2013 Accepted: 18 June 2013

Published: 16 July 2013

\section{References}

1. The Japanese Society for Clinical Renal Transplantation: Annual progress report from the Japanese renal transplant registry: number of renal transplantations in 2008, part 2. ISYOKU 2009, 44:548.

2. Golshayan D, Pascual M: Minimization of calcineurin inhibitors to improve long-term outcomes in kidney transplantation. Transpl Immunol 2008, 20:21.
3. Nankivell BJ, Borrows RJ, Fung CL, O'Connell PJ, Allen RD, Chapman JR: The natural history of chronic allograft nephropathy. N Engl J Med 2003, 349:2326.

4. Nankivell BJ, Borrows RJ, Fung CL, O'Connell PJ, Chapman JR, Allen RD: Calcineurin inhibitor nephrotoxicity: longitudinal assessment by protocol histology. Transplantation 2004, 78:557.

5. Schuler W, Sedrani R, Cottens S, Häberlin B, Schulz M, Schuurman HJ, Zenke $\mathrm{G}$, Zerwes HG, Schreier MH: SDZ RAD, a new rapamycin derivative: pharmacological properties in vitro and in vivo. Transplantation 1997, 64:36.

6. Tedesco-Silva H Jr, Vitko S, Pascual J, Eris J, Magee JC, Whelchel J, Civati G, Campbell S, Alves-Filho G, Bourbigot B, Garcia VD, Leone J, Esmeraldo R, Rigotti P, Cambi V: Haas T; 2306 and 2307 Study Groups: 12-month safety and efficacy of everolimus with reduced exposure cyclosporine in de novo renal transplant recipients. Transpl Int 2007, 20:27.

7. Lorber MI, Mulgaonkar S, Butt KM, Elkhammas E, Mendez R, Rajagopalan PR, Kahan B, Sollinger H, Li Y, Cretin N: Tedesco H; B251 Study Group: Everolimus versus mycophenolate mofetil in the prevention of rejection in de novo renal transplant recipients: a 3-year randomized, multicenter, phase III study. Transplantation 2005, 80:244.

8. Vitko S, Tedesco H, Eris J, Pascual J, Whelchel J, Magee JC, Campbell S, Civati G, Bourbigot B, Alves Filho G, Leone J, Garcia VD, Rigotti P, Esmeraldo R, Cambi V, Haas T, Jappe A, Bernhardt P, Geissler J, Cretin N: Everolimus with optimized cyclosporine dosing in renal transplant recipients: 6-month safety and efficacy results of two randomized studies. Am J Transplant 2004, 4:626.

9. Vitko S, Margreiter R, Weimar W, Dantal J, Kuypers D, Winkler M, Øyen O, Viljoen HG, Filiptsev P, Sadek S, Li Y, Cretin N, Budde K: RAD B201 Study Group: Three-year efficacy and safety results from a study of everolimus versus mycophenolate mofetil in de novo renal transplant patients. Am J Transplant 2005, 5:2521.

10. Nashan B, Curtis J, Ponticelli C, Mourad G, Jaffe J, Haas T: Everolimus and reduced-exposure cyclosporine in de novo renal-transplant recipients: a three-year phase II, randomized, multicenter, open-label study. Transplantation 2004, 78:1332.

11. Chan L, Greenstein S, Hardy MA, Hartmann E, Bunnapradist S, Cibrik D, Shaw LM, Munir L, Ulbricht B, Cooper M: CRADUS09 Study Group: Multicenter, randomized study of the use of everolimus with tacrolimus after renal transplantation demonstrates its effectiveness. Transplantation 2008, 85:821.

12. Tedesco-Silva H Jr, Cibrik D, Johnston T, Lackova E, Mange K, Panis C, Walker R, Wang Z, Zibari G, Kim YS: Everolimus plus reduced-exposure CsA versus mycophenolic acid plus standard-exposure CsA in renal-transplant recipients. Am J Transplant 2010, 10:1401.

13. Dantal J, Francois Berthoux F, Moal M-C, Rostaing L, Legendre C, Genin R, Toupance O, Moulin B, Merville P, Rerolle JP, Bayle F, Westeel PF, Glotz D, Kossari N, Lefrançois N, Charpentier B, Quéré S, Di Giambattista F, Cassuto E: RAD A2420 Study Group: Efficacy and safety of de novo or early everolimus with low cyclosporine in deceased-donor kidney transplant recipients at specified risk of delayed graft function: 12-month results of a randomized, multicenter trial. Transpl Int 2010, 23:1084.

14. Salvadori M, Scolari MP, Bertoni E, Citterio F, Rigotti P, Cossu M, Dal Canton A, Tisone G, Albertazzi A, Pisani F, Gubbiotti G, Piredda G, Busnach G, Sparacino V, Goepel V, Messa P, Berloco P, Montanaro D, Veroux P, Federico S, Bartezaghi M, Corbetta G, Ponticelli C: Everolimus with very lowexposure cyclosporine a in de novo kidney transplantation: a multicenter, randomized, controlled trial. Transplantation 2009, 88:1194.

15. Vitko S, Margreiter R, Weimar W, Dantal J, Viljoen HG, Li Y, Jappe A, Cretin N: RAD B201 Study Group: Everolimus (Certican) 12-month safety and efficacy versus mycophenolate mofetil in de novo renal transplant recipients. Transplantation 2004, 78:1532.

16. Japanese package insert of Certican tablet: [http://www.info.pmda.go.jp/ downfiles/ph/PDF/300242_3999022F1028_1_08.pdf]

17. Basic Principles on Global Clinical Trials: Pharmaceuticals and Medical Devices Agency (PMDA Notification No. 0928010). [http://www.pmda.go.jp/english/ service/pdf/notifications/PFSB-ELD-0928010.pdf]

18. Racusen LC, Colvin RB, Solez K, Mihatsch MJ, Halloran PF, Campbell PM, Cecka MJ, Cosyns JP, Demetris AJ, Fishbein MC, Fogo A, Furness P, Gibson IW, Glotz D, Hayry P, Hunsickern L, Kashgarian M, Kerman R, Magil AJ, Montgomery R, Morozumi K, Nickeleit V, Randhawa P, Regele H, Seron D, Seshan S, Sund S, Trpkov K: Antibody-mediated rejection criteria - an 
addition to the Banff 97 classification of renal allograft rejection. Am J Transplant 2003, 3:708.

19. Coresh J, Astor BC, Greene T, Eknoyan G, Levey AS: Prevalence of chronic kidney disease and decreased kidney function in the adult US population: Third National Health and Nutrition Examination Survey. Am J Kidney Dis 2003, 41:1.

20. Hariharan S, McBride MA, Cherikh WS, Tolleris CB, Bresnahan BA, Johnson CP: Post-transplant renal function in the first year predicts long-term kidney transplant survival. Kidney Int 2002, 62:311.

21. Morozumi K, Thiel G, Albert FW, Banfi G, Gudat F, Mihatsch MJ: Studies on morphological outcome of cyclosporine-associated arteriolopathy after discontinuation of cyclosporine in renal allografts. Clin Nephrol 1992, 38:1-8.

22. Nankivell BJ, Borrows RJ, Fung CL, O'Connell PJ, Chapman JR, Allen RD: Calcineurin inhibitor nephrotoxicity: longitudinal assessment by protocol histology. Transplantation 2004, 78:557-565.

23. Araki K, Turner AP, Shaffer VO, Gangappa S, Keller SA, Bachmann MF, Larsen $C P$, Ahmed R: mTOR regulates memory CD8 T-cell differentiation. Nature 2009, 460:108.

24. Turner AP, Shaffer VO, Araki K, Martens C, Turner PL, Gangappa S, Ford ML, Ahmed R, Kirk AD, Larsen CP: Sirolimus enhances the magnitude and quality of viral-specific CD8(+) T-cell responses to vaccinia virus vaccination in rhesus macaques. Am J Transplant 2011, 11:613.

25. Saemann MD, Haidinger $M$, Hecking M, Hörl WH, Weichhart T: The multifunctional role of mTOR in innate immunity: implications for transplant immunity. Am J Transplant 2009, 9:2655.

doi:10.1186/2047-1440-2-14

Cite this article as: Takahashi et al:: Efficacy and safety of concentrationcontrolled everolimus with reduced-dose cyclosporine in Japanese de novo renal transplant patients: 12-month results. Transplantation Research 2013 2:14

\section{Submit your next manuscript to BioMed Central and take full advantage of:}

- Convenient online submission

- Thorough peer review

- No space constraints or color figure charges

- Immediate publication on acceptance

- Inclusion in PubMed, CAS, Scopus and Google Scholar

- Research which is freely available for redistribution 